\title{
HONEY BEE RESPONSE TO HIGH CONCENTRATIONS OF SOME NEW SPRAY ADJUVANTS
}

\author{
B.J. DONOVAN ${ }^{1}$ and G.S. ELLIOTT ${ }^{2}$
}

${ }^{1}$ Donovan Scientific Insect Research, Canterbury Agriculture and Science Centre, Ellesmere Junction Road, Lincoln. Private Bag 4704, Christchurch ${ }^{2}$ Elliott Chemicals Ltd., PO Box 18-417, Glen Innes, Auckland

Corresponding author: donovanb@crop.cri.nz

\begin{abstract}
The response of honey bees when treated orally and topically to the spray adjuvants Du-Wett ${ }^{\circledR}, \mathrm{Li}^{-} 700^{\circledR}$, Bond $^{\circledR}$ and Bond ${ }^{\circledR}$ Xtra, each at three different concentrations, was evaluated in November 2000 under the OECD Guidelines for Testing of Chemicals of 21 September 1998. The concentrations ranged from $0.1 \%$ to $1.0 \%$, the highest of which were well above those used in the field. Dimethoate at three concentrations was used as a standard, and for the topical test distilled water was used as a non-chemical control. For both tests about 1000 honey bees from the brood combs of a healthy colony were anaesthetized with carbon dioxide, from which bees were treated and held in groups of 10 in cages at $25^{\circ} \mathrm{C}$ and $70 \%$ RH for 48 hours. Each treatment was replicated three times. Despite some mortality for two of the three cages of Bond Xtra at $1 \%$ when applied topically, none of the adjuvants were found to be toxic to honey bees at any concentrations tested.

Keywords: honey bees, adjuvants, OECD Test Guidelines, response, non-
\end{abstract} toxic.

\section{INTRODUCTION}

Adjuvants ('helpful auxiliaries') added to sprays used on fungi, weeds and insects generally have not been considered to have insecticidal properties, and so do not carry labels warning of possible adverse effects on honey bees (Apis mellifera L.). However some surfactants ('surface active agents') used beyond New Zealand have been reported to be toxic to a range of insects other than honey bees (Tattersfield \& Gimingham 1927; Corey \& Langford 1935; Wolfenbarger et al. 1967; Imai et al. 1994). Some surfactants used in New Zealand have been shown to be toxic to honey bees when applied topically with a Burkard Potter spray tower (Citowett ${ }^{\circledR}$, Pulse $^{\circledR}$, Boost $^{\circledR}$ and Ethokem ${ }^{\circledR}$ ), and when fed in sugar syrup $\left(\right.$ Boost $^{\circledR}$ and Ethokem $\left.{ }^{\circledR}\right)$, while seven other surfactants were not toxic to bees (Goodwin \& McBrydie 2000).

Several new adjuvants have recently become available, and because they may be used where contact with honey bees is likely, there is a need to determine whether they display toxicity to honey bees. The OECD Guidelines for the Testing of Chemicals, adopted on 21 September 1998 (OECD 1998), were employed so that test results could be recognized universally.

\section{Materials tested}

\section{METHODS}

Four adjuvants were tested: Du-Wett (a blend of organosilicone and organic surfactants designed to act as a superwetter for improved retention and coverage of horticultural sprays; Elliott Chemicals Ltd.); Li-700 (a phosphatidylcholine/surfactant blend which aids spreading and also improves uptake of systemic plant protection products; Loveland Industries, USA); Bond (a carboxylated synthetic latex sticker); and Bond Xtra (a mix 
of synthetic latex and organosilicone surfactant which acts as a sticker-spreader to improve spray deposition, coverage and rainfastness of agrochemical sprays; Loveland Industries, USA). Three different concentrations of each adjuvant, were tested both topically and orally. The lowest test concentration was that recommended for commercial use, while the next highest concentration was about double the lowest, and the highest was four to five times the lowest.

As recommended by the OECD Guidelines (OECD 1998), three concentrations of Dimethoate were used as a toxic standard. For the topical test a control of distilled water only was employed, while for the oral test the control bees were fed only sugar/ water. Controls and all tests of all concentrations of all materials were replicated three times.

\section{Bees and cages}

For each test, about 1000 adult worker honey bees of the Italian subspecies A. m. ligustica Spinola were collected from brood comb and were lightly anaesthetized with $\mathrm{CO}_{2}$. After topical treatment or during oral treatment, bees were held in groups of 10 in units of three wooden-framed cages measuring $68 \mathrm{~mm}$ long, $25 \mathrm{~mm}$ wide and $25 \mathrm{~mm}$ deep. The top and bottom were covered in wire mesh with gaps about $1.5 \mathrm{~mm}$ wide, and the unit of three cages stood on small bars at each end to allow full circulation of air through the cages. Feeder tubes holding up to $8 \mathrm{ml}$ were fitted through a hole at one end of each cage (Fig. 1). Three cages together held 30 bees from each treatment concentration. Bees were held in the dark at $25^{\circ} \mathrm{C}$ and $70 \% \mathrm{RH}$, but normal lighting was used when survival was being evaluated.

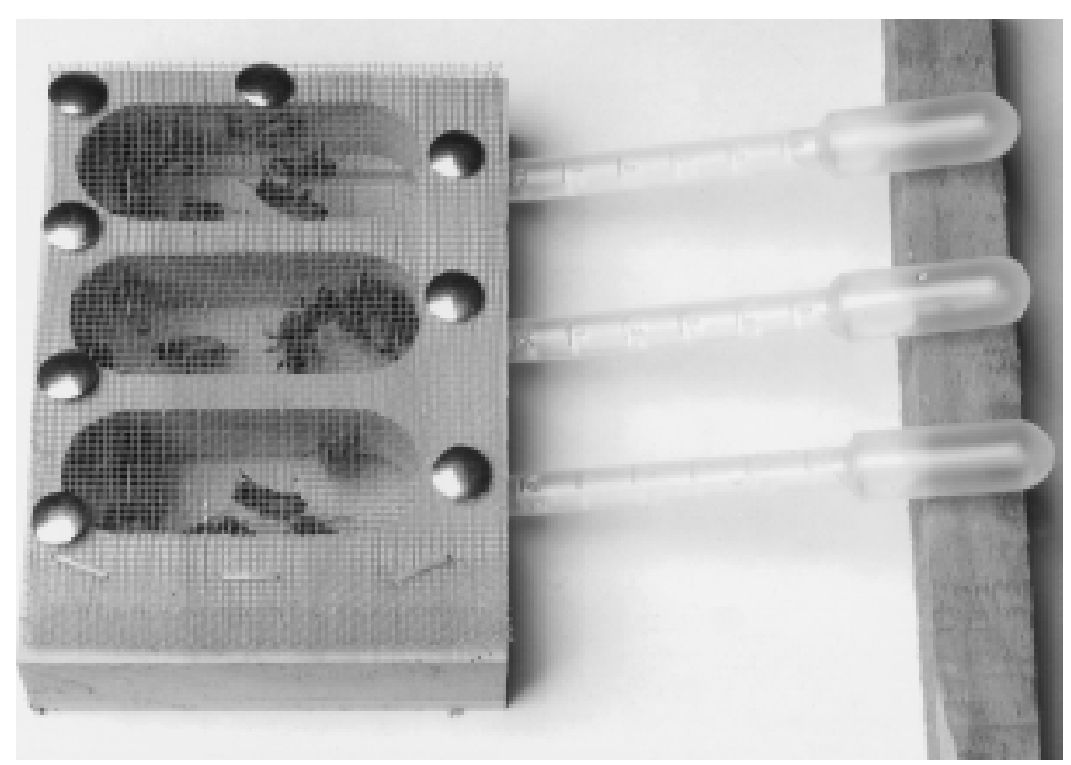

FIGURE 1: Three test cages, each containing 10 honey bees.

\section{Topical tests}

Test materials were diluted with distilled water, and $1 \mu \mathrm{l}$ of test solution was applied with a Gilson micropipette to the dorsum of the mesosoma of each anaesthetized bee. Each cage containing 10 treated bees was supplied with ca $6 \mathrm{ml}$ of 50:50 sugar:water (vol:vol) in the feeder tube. 


\section{Oral tests}

Test material $(200 \mathrm{ml})$ at the appropriate concentration was dispersed in $3 \mathrm{ml}$ of 50:50 sugar:water (vol:vol) per feeding tube. The volume of fluid removed over the duration of the test was noted.

\section{Assessment and statistical analysis}

The number of dead bees per cage was assessed at 4,24 and $48 \mathrm{~h}$ after treatment. Probit analysis was used to estimate $\mathrm{LD}_{50}$ values where the data showed a dose response. Where there was no additional mortality with increasing dose, average mortality was estimated using a generalized linear model analysis, assuming a binomial error distribution and a logit link function. Mortality due to each of the treatments was adjusted for control mortality, using the correction of Abbott (1925). The 95\% confidence limits were calculated on the scale of the linear predictor and backtransformed to percentages. Where there was no mortality, upper $95 \%$ confidence limits for percent mortality were calculated assuming standard binomial distribution theory.

\section{Topical test}

RESULTS

One control bee was dead at $4 \mathrm{~h}$, and three were dead after $24 \mathrm{~h}$. One bee appeared dead at the Du Wett $0.1 \%$ dose at $4 \mathrm{~h}$, but had partially recovered at $12 \mathrm{~h}$ and had fully recovered at $24 \mathrm{~h}$. At each assessment time mortality at the highest dose was less than that of the controls. Mortality at each dose of Li-700 and Bond at each observation time was less than that of the controls. Mortality for Bond Xtra was the same as or lower than the controls at each observation time for the two lower doses, but was $30 \%, 23 \%$ and $33 \%$ for the highest dose at 4,24 and $48 \mathrm{~h}$ respectively. The additional mortality over that of the controls was thus $27 \%, 13 \%$ and $23 \%$ respectively. Since the standard errors of these estimates are $16 \%, 14 \%$ and $15 \%$ the additional mortality is not significantly greater than zero. $\mathrm{LD}_{50}$ values cannot be estimated, but they were greater than $1.0 \%$ at any of the assessment times.

Mortality after 24 and $48 \mathrm{~h}$ for Dimethoate was $100 \%$ at all three doses. Therefore the $\mathrm{LD}_{50}$ after $24 \mathrm{~h}$ was less than $200 \mathrm{ml} / 100$ litres.

\section{Oral test}

An estimated 50-600 $\mu \mathrm{l}$ of fluid was consumed per functioning feeding tube. Control mortality was zero, so no adjustment to treatment mortality was necessary. For Li-700 $1 \%$, one bee died from loss of its head, so was excluded from analysis. For Bond Xtra $1 \%$, the feeder in one cage was found to be blocked, and nine of the 10 bees died. No bees died in the other two replicate cages, so the first cage was omitted from the analysis. Because there was just one mortality for Du Wett at $4 \mathrm{~h}$ at $0.25 \%$, there was no dose response, so $\mathrm{LD}_{50}$ values cannot be calculated. The average mortality over all three doses $(\mathrm{n}=90)$ at each observation time was $1.1 \%$ (with $95 \%$ confidence limits of $0.2 \%$ and 7.5\%). There was no mortality at any of the doses of Li-700, Bond or Bond Xtra. After adjusting for the headless bee and the bees that starved, the upper $95 \%$ confidence limits for mortality at the highest dose for the three adjuvants were $12 \%, 12 \%$ and $17 \%$ respectively.

The mortality after $24 \mathrm{~h}$ for Dimethoate was $100 \%$ for all three doses. Therefore the $\mathrm{LD}_{50}$ after $24 \mathrm{~h}$ was less than $200 \mathrm{ml} / 100$ litres.

\section{DISCUSSION AND CONCLUSIONS}

Despite some mortality for Bond Xtra at $1 \%$ when applied topically, this was not significantly greater than zero, and the $\mathrm{LD}_{50}$ for this adjuvant was found to be greater than $1 \%$. All concentrations of all adjuvants tested topically and orally under the OECD test protocols were non-toxic to honey bees at doses well above those used in the field. 
TABLE 1: Total number of dead bees in all three replicates out of a total of 30 bees, for each concentration of treatment material at the time interval indicated, when treated either topically or orally.

\begin{tabular}{|c|c|c|c|c|c|c|c|}
\hline \multirow[b]{2}{*}{ Material } & \multirow[b]{2}{*}{ Concentration } & \multicolumn{3}{|c|}{ Topical } & \multicolumn{3}{|c|}{ Oral } \\
\hline & & $4 \mathrm{~h}$ & $24 \mathrm{~h}$ & $\overline{48 \mathrm{~h}}$ & $4 \mathrm{~h}$ & $24 \mathrm{~h}$ & $\overline{48 h}$ \\
\hline \multirow[t]{3}{*}{ Du-Wett } & $0.1 \%$ & 1 & 0 & 0 & 0 & 0 & 0 \\
\hline & $0.25 \%$ & 2 & 4 & 4 & 1 & 1 & 1 \\
\hline & $0.5 \%$ & 0 & 2 & 3 & 0 & 0 & 0 \\
\hline \multirow[t]{3}{*}{ Li-700 } & $0.25 \%$ & 0 & 1 & 1 & 0 & 0 & 0 \\
\hline & $0.5 \%$ & 0 & 1 & 1 & 0 & 0 & 0 \\
\hline & $1.0 \%$ & 0 & 1 & 1 & $1^{1}$ & $1^{1}$ & $1^{1}$ \\
\hline \multirow[t]{3}{*}{ Bond } & $0.125 \%$ & 0 & 1 & 1 & 0 & 0 & 0 \\
\hline & $0.25 \%$ & 1 & 2 & 2 & 0 & 0 & 0 \\
\hline & $0.5 \%$ & 0 & 2 & 2 & 0 & 0 & 0 \\
\hline \multirow[t]{3}{*}{ Bond Xtra } & $0.2 \%$ & 1 & 1 & 1 & 0 & 0 & 0 \\
\hline & $0.5 \%$ & 1 & 2 & 2 & 0 & 0 & 0 \\
\hline & $1.0 \%$ & 9 & 7 & 10 & 0 & $2^{2}$ & $9^{2}$ \\
\hline \multirow[t]{3}{*}{ Dimethoate } & $200 \mathrm{ml} / 100$ litre & 24 & 30 & 30 & 25 & 30 & 30 \\
\hline & $300 \mathrm{ml} / 100$ litre & 22 & 30 & 30 & 30 & 30 & 30 \\
\hline & $400 \mathrm{ml} / 100$ litre & 28 & 30 & 30 & 28 & 30 & 30 \\
\hline Control & & 1 & 3 & 3 & 0 & 0 & 0 \\
\hline
\end{tabular}

${ }^{1}$ Head lost, excluded from analysis.

${ }^{2}$ Feeder blocked in one replicate and bees died of starvation; excluded from analysis.

Because the test methods used and the materials tested by Goodwin \& McBrydie (2000) are different to those used in our study, the results of the two studies cannot be compared directly. Surfactants and adjuvants are used with sprays because they enhance the properties of sprays, and neither the work described in this paper nor the work of Goodwin \& McBrydie (2000) evaluated the effects on bees of sprays containing surfactants or adjuvants. However, we agree with the conclusions of Goodwin \& McBrydie (2000) that field trials are necessary to determine the effects of the materials on honey bees. We also endorse their suggestion that materials such as surfactants and adjuvants should be subjected to the agrichemical registration process, and that where toxicity is evident, the materials be labelled accordingly. Nevertheless, because all the materials tested in this trial were non-toxic to honey bees, even at concentrations much higher than those recommended for use in the field, there is a strong implication that they themselves will not be toxic to honey bees in the field.

\section{ACKNOWLEDGEMENTS}

We thank Dr John Marshall, Mr Marlon Stufkens and Mr Andrew Wallace of Crop and Food Research, Lincoln, for advice and loan of some equipment, and for the statistical analysis respectively.

\section{REFERENCES}

Abbott, W.S. 1925: A method of computing the effectiveness of an insecticide. J. Econ. Entomol. 18: 265-267.

Corey, E.N.; Langford, G.S. 1935: Sulfated alcohols in insecticides. J. Econ. Entomol. 28: $257-260$

Goodwin, R.M.; McBrydie, H.M. 2000: Effect of surfactants on honey bee survival. N.Z. Plant Prot. 53: 230-234. 
Imai, T.; Tsuchiya, S.; Monita, K.; Fujimori, T. 1994: Surface tension-dependent surfactant toxicity on the green peach aphid, Myzus persicae (Sulzer) (Hemiptera: Aphididae). Appl. Entomol. Zool. 29 (3): 389-393.

OECD 1998: www.oecd.org (25/02/00)

Tattersfield, F.; Gimingham, C.T. 1927: studies on contact insecticides. Part IV. The insecticidal action of the fatty acids, their methyl esters and sodium and ammonium salts. Ann. Appl. Biol. 14: 331-358.

Wolfennbarger, D.A.; Lukefahr, M.J.; Lowry, W.L. 1967: Toxicity of surfactants and surfactant-insecticide combinations to the bollworm, tobacco budworm, and pink bollworm. J. Econ. Entomol. 60: 902-904. 